Xianglong $\mathrm{NI}$

Jianmin ZHAO

Wenyuan SONG

Chiming GUO

Haiping LI

\title{
NONLINEAR DEGRADATION MODELING AND MAINTENANCE POLICY FOR A TWO-STAGE DEGRADATION SYSTEM BASED ON CUMULATIVE DAMAGE MODEL
}

\section{SYSTEM CHARAKTERYZUJĄCY SIĘ DWUETAPOWYM PROCESEM DEGRADACJI: NIELINIOWE MODELOWANIE DEGRADACJI ORAZ WYZNACZANIE STRATEGII EKSPLOATACJI SYSTEMU NA PODSTAWIE MODELU SUMOWANIA USZKODZEŃ}

This paper attempts to take into account a two-stage degradation system which degradation rate is non-stationary and change over time. The system degradation is thought to be caused by shocks, and system degradation model is established based on cumulative damage model. The nonlinear degradation process is expressed by different shock damage and shock counting. And shock damage and shock counting are assumed to be Gamma distribution and non-homogeneous Poisson process, respectively. On the basis of these, system reliability model and nonlinear degradation model are given. In order to optimal maintenance policy for considered system, adaptive maintenance policy and time-dependent maintenance policy are studied, and mean maintenance cost rate is established to evaluate the maintenance policies. Numerical examples are given to analyze the influences of degradation model parameters and find optimal maintenance policy for considered system.

Keywords: two-stage, nonlinear, degradation modeling, cumulative damage model, maintenance policy.

\begin{abstract}
W przedstawionym artykule badano system, w którym proces degradacji zachodzi dwuetapowo, a szybkość degradacji jest zmien$n a$ w czasie. Przyjęto, że do degradacji systemu dochodzi w wyniku wstrzasów. Model degradacji systemu oparto na modelu sumowania uszkodzeń. Nieliniowy proces degradacji określono jako taki, w którym uszkodzenie powodowane wstrząsem oraz częstotliwość wstrząsów sq wartościami zmiennymi. Przyjęto, że uszkodzenie powodowane wstrząsem ma rozktad gamma a częstotliwość wstrzasów jest niejednorodnym procesem Poissona. Na tej podstawie utworzono model niezawodności systemu oraz model degradacji nieliniowej. W celu opracowania optymalnej strategii eksploatacji dla rozpatrywanego systemu, rozważono dwa typy strategii utrzymania ruchu: strategię adaptacyjna oraz strategię czasowo-zależna. Strategie te oceniano określając średni poziom kosztów eksploatacji. Przyklady numeryczne postużyly do analizy wpływu parametrów modelu degradacji oraz pozwolity określić optymalna strategię utrzymania dla rozpatrywanego systemu.
\end{abstract}

Stowa kluczowe: dwu-etapowy, nieliniowy, modelowanie degradacji, model sumowania uszkodzeń, strategia eksploatacji.

\section{Nomenclature}

$M_{k} \quad$ The $k$ th $(k=1,2)$ stage of system degradation process

$x_{i}^{k} \quad$ System damage value due to the ith shock in degradation stage $M_{k}$

$N_{k} \quad$ The number of shock counting in degradation stage $M_{k}$

$t_{c} \quad$ The change-point that degradation stage from $M_{1}$ to $M_{2}$

$Y(t) \quad$ System whole degradation level at time $t$

$Y^{k}(t) \quad$ Cumulative degradation quantity just for the $k$ th stage

$\lambda_{k}(t)$ The Poisson parameter that system at time $t$ in degradation stage $M_{k}$

$g_{c}(t) \quad$ The probability density function of change-point $t_{c}$

$Y_{f} \quad$ System failure threshold

$T_{f} \quad$ The time point of system failure

$Y_{k} \quad$ System alarm threshold in degradation stage $M_{k}$

$T_{i} \quad$ The $i$ th inspection time

$\Delta T_{k} \quad$ The interval of inspection in degradation stage $M_{k}$
$\Delta T^{i} \quad$ The $i$ th interval of inspection

$E(C)$ Mean maintenance cost rate

$C_{I} \quad$ Unit cost of an inspection action

$C_{P} \quad$ Unit cost of a preventive maintenance action

$C_{C} \quad$ Unit cost of a corrective maintenance action

$E[C(T)]$ Total maintenance cost in a renewal cycle $T$

$E[T] \quad$ Mean time length of renewal cycle $T$

$E\left[N_{I}(T)\right]$ Average number of inspection counting in a renewal cycle $T$

$P_{P} \quad$ Probability of performing preventive maintenance in a renewal cycle $T$

$P_{C} \quad$ Probability of performing corrective maintenance in a renewal cycle $T$

\section{Introduction}

Degradation analysis is a research hotspot for prognostic and health management (PHM), which can be used for estimating failuretime distribution [16], predicting remaining useful life (RUL) distri- 
bution [3, 23] and exploring preventive maintenance policy [12, 25]. Especially, degradation process modeling is an important approach for evaluating the reliability of high reliable products $[1,2]$.

Stationary degradation process has been studied intensively to optimize maintenance problems. However, the degradation process of some systems present two-stage feature due to the influences of internal mechanism and external environment etc [7], where the degradation rate is suddenly increased. For example, the vibration-based degradation signals of bearings [8] and vibration signals special frequency band energy of gearboxes [14] exhibit two-stage characteristic in degradation test. There are two typical models with independent random increment, continuous time model [7] and cumulative damage model [21], that can be used to present system degradation process. Some researchers have studied on the degradation process modeling for two-stage degradation system. But in most articles $[5,6,17$, 19] the degradation processes are assumed to be continuous Gamma process, and degradation rates for different degradation stages are presented by different Gamma parameters. Wiener process is also used for two-stage degradation modeling [9]. In existing studies, the degradation process is mostly supposed to be continuous and modelling by continuous time model. But for some systems, their degradations are caused by shocks and their increases of degradation levels are step, such as reciprocating machine. Furthermore, some system degradation quantities, which are collected by interval monitoring, can be considered as causing by shocks, even if the system degradation process is continuous.

Condition-based maintenance (CBM) is an importance approach for reducing maintenance cost to gradual degradation system [11]. This maintenance decision-making method is also effective for twostage degradation system. But the degradation rate suddenly increased will bring significant impact on maintenance policy. On the basis that change-point of degradation rate can be monitored perfected, Saassouh [19] put forward an activation zone to plan the maintenance action for a two-stage system. Fouladirad $[5,7]$ proposed an adaptive maintenance policy based on online change detection procedures, where alarm thresholds were diverse in different degradation stage as the degradation rate change. Ponchet [17] assumed that change-point of degradation rate cannot be monitored, and he developed two condition-based maintenance optimization models with and without considering the change-point in system degradation process, respectively, the numerical results showed that it can bring considerable benefits if degradation rate changing was considered in maintenance policy. In these existing studies, the mean degradation rates in the first stage and the second stage were both considered as fixed, and the increased process of degradation level presented linear. In 2011, Fouladirad [6] took into account a system with time-dependent degradation rate after change-point, but the degradation process was assumed to be continuous Gamma process. Meanwhile, he studied a condition-based maintenance policy with time-dependent alarm thresholds in the second degradation stage. But the interval of inspection was considered as fixed no matter how the degradation rate changed, it was difficult to achieve the best maintenance policy.

This paper considers degradation modeling and maintenance policy for a two-stage degradation system, which degradation process is nonlinear and degradation rate is changed over time in both stages. The main contributions of this study are: (a) Considering some system degradation are caused by shocks, cumulative damage model is used for two-stage degradation process modeling, and the degradation rate are presented by different shock damage and shock counting. (b) As the degradation rate is changed over time, a time-dependent maintenance policy is proposed, which the interval of inspection is time-dependent.

The remainder of this paper is organized as follows. In section 2 , a two-stage degradation system is presented and system degradation modelling method is studied. Two kinds of maintenance policy and maintenance policy evaluation method are given in section 3 . In section 4, numerical examples are used to analyze the influences of different parameters for two-stage degradation model. Conclusions are made in section 5 .

\section{Nonlinear degradation modeling for a two-stage degradation system}

\subsection{Two-stage degradation system}

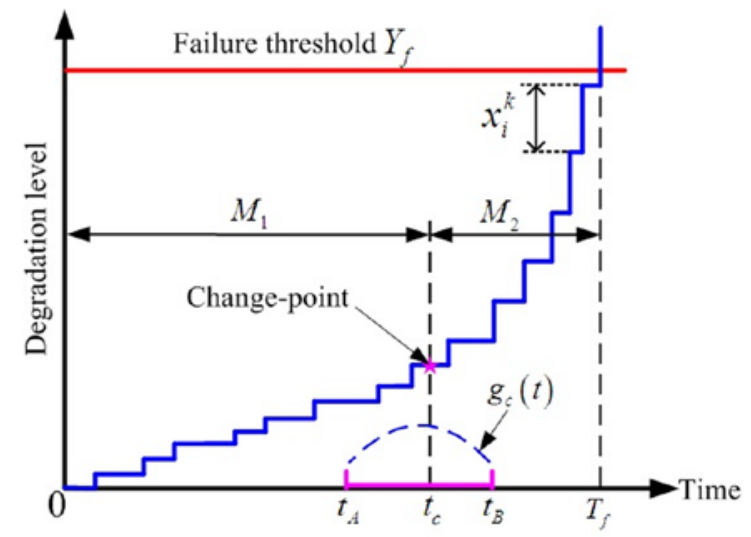

Fig. 1. Two-stage degradation process

The system with two-stage degradation process considered in this paper is described as follows (as shown in Fig. 1):

- In system degradation process, mean degradation rate suddenly increase at a random time point. And the time point is denoted by change-point $t_{c}$. Before $t_{c}$, system is in nominal degradation stage $M_{1}$ and mean degradation rate is small. After $t_{c}$, system is in accelerated degradation stage $M_{2}$ and mean degradation rate is large. The degradation rate of whole degradation process is non-stationary and become larger in terms of working time, so the degradation process is nonlinear.

- System degradation level at time $t$ can be summarized by a scalar aging variable $Y(t)$. There is no doubt that $Y(t)$ is an increasing stochastic scalar. System initial state is assumed to be intact in this paper, namely $Y(0)=0$. System will be considered as failed if degradation level $Y(t)$ exceeds failure threshold $Y_{f}$. And system stops functioning either for economic reasons or for safety reasons when $Y(t)$ is greater than $Y_{f}$.

- System degradation process can be thought as step, and degradation level is the sum of large numbers of tiny damage values. Therefore, the whole degradation level at working time $t$ can be expressed by cumulative damage model [22] as

$$
Y(t)=\sum_{i=1}^{N_{1}} x_{i}^{1} \cdot \mathrm{I}_{\left\{t \leq t_{c}\right\}}+\left(\sum_{i=1}^{N_{1}} x_{i}^{1}+\sum_{j=1}^{N_{2}} x_{j}^{2}\right) \cdot \mathrm{I}_{\left\{t>t_{c}\right\}}
$$

Where $N_{k}(k=1,2)$ is the number of shock counting in degradation stage $M_{k}, x_{i}^{k}$ is the shock damage value for $i$ th shock in degradation stage $M_{k}$. $I_{\{E\}}=1$ if $E$ is true and otherwise $I_{\{E\}}=0$. When $t>t_{c}$, degradation level is the sum of the damage in the first stage $M_{1}$ and the second stage $M_{2}$. In this case, the working time length of system degradation in stage $M_{1}$ is $t_{c}$ and in stage $M_{2}$ is $t-t_{c}$.

As the characteristic of cumulative damage model [17,22], system degradation rate is determined by damage value per shock and shock counting per unit time. In this paper, in order to show shock counting 
changes over time, the shock counting $N_{k}$ is assumed to be non-homogeneous Poisson process (NHPP) and with Poisson parameter $\lambda_{k}(t)$ at time $t$ in stage $M_{k}[4,24]$. That is, the probability of shock counting $N_{k}$ equals to $m$ during $(0, t)$ in stage $M_{k}$ can be written as:

$$
P\left(N_{k}=m\right)=\frac{\left(\int_{0}^{t} \lambda_{k}(u) d u\right)^{m}}{m !} \cdot e^{-\int_{0}^{t} \lambda_{k}(u) d u}
$$

Because all the shocks are independent in whole degradation process, the probability of shock counting in the first stage $N_{1}=m$ and in the second stage $N_{2}=n$ is:

$P\left(N_{1}=m, N_{2}=n\right)=\frac{\left(\int_{0}^{t_{c}} \lambda_{1}(u) d u\right)^{m}}{m !} \cdot \frac{\left(\int_{t_{c}}^{t} \lambda_{2}\left(\tau-t_{c}\right) d \tau\right)^{n}}{n !} \cdot e^{-\int_{0}^{t_{c}} \lambda_{1}(u) d u-\int^{t} \lambda_{2}\left(\tau-t_{c}\right) d \tau}$

As Gamma process is suitable for describing monotonic degradation $[13,15]$, shock damage is assumed to be Gamma distribution in this study (It is important to note that the Gamma distribution is used for shock damage by a shock in this study, but in literatures [5-7, 17, 19] the Gamma distribution is used for degradation level of whole continuous degradation process). In this paper, if the ith shock in stage

$M_{k}$ occurs at $t_{i}$, the shock damage is $x_{i}^{k} \sim G a\left(\alpha_{k}\left(t_{i}\right), \beta_{k}\right)\left(\alpha_{k}\left(t_{i}\right)\right.$

is shape-parameter, $\beta_{k}$ is scale-parameter). $Y^{k}(t)$ is the cumulative degradation quantity just for the $k$ th stage (namely whole degradation level $Y(t)=Y^{1}(t)+Y^{2}(t)$ when $\left.t>t_{c}\right)$. Meanwhile, as every shock is independent in degradation process, it can be known from Gamma theorem that $Y^{k}(t)$ also follows Gamma distribution. $N_{k}$ is the shock counting in stage $M_{k}$. When $N_{k}=1,2,3, \cdots, Y^{k}(t)$ can be written as:

$$
Y^{k}(t)=\sum_{i=1}^{N_{k}} x_{i}^{k} \sim G a\left(\sum_{i=1}^{N_{k}} \alpha_{k}\left(t_{i}\right), \beta_{k}\right)
$$

The corresponding probability density function (PDF) is:

$$
f_{N_{k}}^{k}(y)=\frac{1}{\Gamma\left(\sum_{i=1}^{N_{k}} \alpha_{k}\left(t_{i}\right)\right) \cdot \beta_{k}^{i=1} \alpha_{k}\left(t_{i}\right)} \cdot y^{\sum_{i=1}^{N_{k}} \alpha_{k}\left(t_{i}\right)-1} \cdot e^{-y / \beta_{k}} \cdot \mathrm{I}_{\{y \geq 0\}}
$$

Where $\Gamma$ is the Euler's Gamma function, $\Gamma(\alpha)=\int_{0}^{\infty} u^{\alpha-1} e^{-u} d u$.

When $N_{k}=0$, the considered system is undamaged in degradation stage $M_{k}$ and $Y^{k}(t)=0$.

\subsection{Reliability modeling}

There are many reasons can cause the transition of degradation rate. Therefore, in engineering practice, change-point $t_{c}$ should be not a fixed parameter but a variable in degradation process. And it is difficult to monitor the specific time point of change-point $t_{c}$ in engineering. But observing some system degradation data and experimental data, it can be found that the change-point mostly falls in a certain range. Moreover, the change-point information can be obtained by statistical from degradation data. In this paper, it is assumed that change-point $t_{c}$ falls in time interval $\left[t_{A}, t_{B}\right]$ with PDF $g_{c}(t)$ and $\int_{t_{A}}^{t_{B}} g_{c}(t) d t=1$, as shown in Fig. 1 .

The system is reliable when degradation level $Y(t)$ does not exceed the failure threshold $Y_{f}$. As key parameters, shock damage $x_{i}^{k}$, Poisson parameter $\lambda_{k}(t)$ and change-point $t_{c}$ all should be considered in reliability modeling of two-stage degradation system. System reliability modeling is divided into three periods, before change-point $\left(0 \leq t \leq t_{A}\right)$, after change-point $\left(t>t_{B}\right)$ and change-point interval $\left(t_{A}<t \leq t_{B}\right)$.

When $0 \leq t \leq t_{A}$, the system reliability is:

$$
\begin{aligned}
R_{1}(t) & =P\left(Y(t)<Y_{f}\right)=P\left(N_{1}=0\right)+\sum_{m=1}^{\infty} P\left(\sum_{i=1}^{N_{1}} x_{i}^{1}<Y_{f} \mid N_{1}=m\right) \cdot P\left(N_{1}=m\right) \\
& =e^{-\lambda_{1} t}+\sum_{m=1}^{\infty}\left(\int_{0}^{Y_{f}} f_{m \alpha_{1}, \beta_{1}}(w) d w \cdot \frac{\left(\lambda_{1} t\right)^{m}}{m !}\right) \cdot e^{-\lambda_{1} t}
\end{aligned}
$$

When $t>t_{B}$, the system reliability is:

$$
\begin{aligned}
R_{2}(t)= & P\left(Y(t)<Y_{f}\right) \\
= & P\left(N_{1}=0, N_{2}=0\right)+\sum_{m=1}^{\infty} P\left(\sum_{i=1}^{N_{1}} x_{i}^{1}<Y_{f} \mid N_{1}=m\right) \cdot P\left(N_{1}=m\right) \cdot P\left(N_{2}=0\right)+ \\
& P\left(N_{1}=0\right) \cdot \sum_{n=1}^{\infty} P\left(\sum_{j=1}^{N_{2}} x_{j}^{2}<Y_{f} \mid N_{2}=n\right) \cdot P\left(N_{2}=n\right)+\sum_{m=1}^{\infty} \sum_{n=1}^{\infty}\left(\sum_{i=1}^{N_{1}} x_{i}^{1}+\sum_{j=1}^{N_{2}} x_{j}^{2}<Y_{f} \mid N_{1}=m, N_{2}=n\right) \\
= & \int_{t_{A}}^{t_{B}}\left(e^{-\lambda_{1} u-\lambda_{2}(t-u)} \cdot g_{c}(u)\right) d u+\int_{t_{A}}^{t_{B}}\left(\sum_{m=1}^{\infty}\left(\int_{0}^{Y_{f}} f_{m \alpha_{1}, \beta_{1}}(w) d w \cdot \frac{\left(\lambda_{1} u\right)^{m}}{m !}\right) \cdot e^{-\lambda_{1} u-\lambda_{2}(t-u)} \cdot g_{c}(u)\right) d u+ \\
& \int_{t_{A}}^{t_{B}}\left(\sum_{n=1}^{\infty}\left(\int_{0}^{Y_{f}} f_{n \alpha_{2}, \beta_{2}}(v) d v \cdot \frac{\left(\lambda_{2}(t-u)\right)^{n}}{n !}\right) \cdot e^{-\lambda_{1} u-\lambda_{2}(t-u)} \cdot g_{c}(u)\right) d u+ \\
& \int_{t_{A}}^{t_{B}}\left(\sum_{m=1}^{\infty} \sum_{n=1}^{\infty}\left(\int_{0}^{Y_{f} Y_{f}-w} \int_{0}^{m}\left(f_{m \alpha_{1}, \beta_{1}}(w) \cdot f_{n \alpha_{2}, \beta_{2}}(v)\right) d v d w \cdot \frac{\left(\lambda_{1} u\right)^{m}}{m !} \cdot \frac{\left(\lambda_{2}(t-u)\right)^{n}}{n !}\right) \cdot e^{-\lambda_{1} u-\lambda_{2}(t-u)} \cdot g_{c}(u)\right) d u
\end{aligned}
$$


The same to formulas (6) and (7), when $t_{A}<t \leq t_{B}$, the system reliability is:

$$
\begin{aligned}
R_{3}(t)= & P\left(Y(t)<Y_{f} \mid t_{A}<t \leq t_{B}\right) \\
= & P\left(Y(t)<Y_{f} \mid t_{A}<t \leq t_{c}\right) \cdot P\left(t_{A}<t \leq t_{c}\right)+P\left(Y(t)<Y_{f} \mid t_{c}<t \leq t_{B}\right) \cdot P\left(t_{c}<t \leq t_{B}\right) \\
= & \left(e^{-\lambda_{1} t}+\sum_{m=1}^{\infty}\left(\int_{0}^{Y_{f}} f_{m \alpha_{1}, \beta_{1}}(w) d w \cdot \frac{\left(\lambda_{1} t\right)^{m}}{m !}\right) \cdot e^{-\lambda_{1} t}\right) \cdot \int_{t}^{t_{B}} g_{c}(u) d u+ \\
& \int_{t_{A}}^{t}\left(e^{-\lambda_{1} u-\lambda_{2}(t-u)} \cdot g_{c}(u)\right) d u+\int_{t_{A}}^{t}\left(\sum_{m=1}^{\infty}\left(\int_{0}^{Y_{f}} f_{m \alpha_{1}, \beta_{1}}(w) d w \cdot \frac{\left(\lambda_{1} u\right)^{m}}{m !}\right) \cdot e^{-\lambda_{1} u-\lambda_{2}(t-u)} \cdot g_{c}(u)\right) d u+ \\
& \int_{t_{A}}^{t}\left(\sum_{n=1}^{\infty}\left(\int_{0}^{Y_{f}} f_{n \alpha_{2}, \beta_{2}}(v) d v \cdot \frac{\left(\lambda_{2}(t-u)\right)^{n}}{n !}\right) \cdot e^{-\lambda_{1} u-\lambda_{2}(t-u)} \cdot g_{c}(u)\right) d u+ \\
& \int_{t_{A}}^{t}\left(\sum_{m=1}^{\infty} \sum_{n=1}^{\infty}\left(\int_{0}^{Y_{f} Y_{f}-w} \int_{0}^{n}\left(f_{m \alpha_{1}, \beta_{1}}(w) \cdot f_{n \alpha_{2}, \beta_{2}}(v)\right) d v d w \cdot \frac{\left(\lambda_{1} u\right)^{m}}{m !} \cdot \frac{\left(\lambda_{2}(t-u)\right)^{n}}{n !}\right) \cdot e^{-\lambda_{1} u-\lambda_{2}(t-u)} \cdot g_{c}(u)\right) d u
\end{aligned}
$$

\subsection{Nonlinear degradation modeling}

In general, the degradation rate is gradually increasing with the increase of system degradation level. In degradation modeling based on cumulative damage model, the degradation rate is determined by damage value of per shock and shock counting per unit time. In other words, any change of shock damage or shock counting, the system degradation rate is affected. Therefore, both shock damage and shock counting should be considered in the transition of degradation rate.

\subsubsection{Shock damage change}

In order to simplify the calculation, it is assumed that the relationship between the damage values of two consecutive shocks is proportional. The shape-parameter of $(i+1)$ th shock is $q_{k}$ times as large as $i$ th shock in stage $M_{k}$, namely $\alpha_{k}\left(t_{i+1}\right)=q_{k} \cdot \alpha_{k}\left(t_{i}\right) \quad\left(q_{k}>0, i=1,2,3, \cdots\right)$.

The shape-parameter of the first shock in stage $M_{k}$ is $\alpha_{k}\left(t_{1}\right)=\alpha_{k}$, and the $(i+1)$ th shock is $\alpha_{k}\left(t_{i+1}\right)=\left(q_{k}\right)^{i} \cdot \alpha_{k}$. Therefore, when the shock counting in stage $M_{k}$ is $N_{k}$, the equation (4) $\left(q_{k} \neq 1\right)$ becomes:

$$
Y^{k}(t)=\sum_{i=1}^{N_{k}} x_{i}^{k} \sim G a\left(\frac{\left(1-\left(q_{k}\right)^{N_{k}}\right) \alpha_{k}}{1-q_{k}}, \beta_{k}\right)
$$

When $q_{k}>1$, the shock damage shows increasing trend; when $q_{k}<1$, the shock damage shows decreasing trend; when $q_{k}=1$, system degradation process is linear, and:

$$
Y^{k}(t)=\sum_{i=1}^{N_{k}} x_{i}^{k} \sim G a\left(N_{k} \alpha_{k}, \beta_{k}\right)
$$

\subsubsection{Shock counting change}

Shock counting per unit time is associated with system working time. Hence, the probability of shock counting is best related to work- ing time. In this paper, it is assumed that Poisson parameter $\lambda_{k}(t)$ is variable function and shows as follows:

$$
\lambda_{k}(t)=\lambda_{k} \eta_{k} t^{\eta_{k}-1} \quad\left(\lambda_{k}, \eta_{k}>0\right)
$$

Therefore, the probability equations (2) and (3) of shock counting become:

$$
P\left(N_{k}=m\right)=\frac{\left(\lambda_{k} t^{\eta_{k}}\right)^{m}}{m !} \cdot e^{-\lambda_{k} t^{\eta_{k}}}
$$

$P\left(N_{1}=m, N_{2}=n\right)=\frac{\left(\lambda_{1} t^{\eta_{1}}\right)^{m}}{m !} \cdot \frac{\left(\lambda_{2}\left(t-t_{c}\right)^{\eta_{2}}\right)^{n}}{n !} \cdot e^{-\lambda_{1} t^{\eta_{1}}-\lambda_{2}\left(t-t_{c}\right)^{\eta_{2}}}$

It is similar to Weibull process, when $0<\eta_{k}<1$, the time interval of two consecutive shocks shows increasing trend; when $\eta_{k}>1$, the time interval of two consecutive shocks shows decreasing trend; when $\eta_{k}=1$, the mean time interval of two consecutive shocks are fixed, and the shock process is a homogeneous Poisson process.

\section{Maintenance policy}

Research of maintenance decision-making is one of focuses for two-stage degradation modeling. As CBM is an effective maintenance policy method for various systems, CBM policy is chose to monitor considered system for the purpose of reducing maintenance cost. In the framework of this study, there are three possible maintenance actions are considered, inspection, preventive maintenance and corrective maintenance, respectively.

\subsection{Adaptive maintenance policy}

According to the characteristic that degradation rate is diverse in different degradation stage for two-stage degradation system, Saas- 
souh et al. [5, 7, 19] put forward adaptive maintenance policy. And this maintenance policy has been proved to be useful.

In adaptive maintenance policy, the alarm threshold $\left(Y_{A}\right)$ and interval of inspection $(\Delta T)$ are defined as follows:

$$
\begin{gathered}
Y_{A}=Y_{1} \cdot \mathrm{I}_{\left\{t \leq t_{c}\right\}}+Y_{2} \cdot \mathrm{I}_{\left\{t>t_{c}\right\}} \\
\Delta T=\Delta T_{1} \cdot \mathrm{I}_{\left\{t \leq t_{c}\right\}}+\Delta T_{2} \cdot \mathrm{I}_{\left\{t>t_{c}\right\}}
\end{gathered}
$$

Set $Y_{k}$ as the alarm threshold and $\Delta T_{k}$ as the interval of inspection for degradation stage $M_{k}$. After the $i$ th inspection (the inspection time is $T_{i}$ ) in degradation stage $M_{k}$, the possible maintenance actions which can put into practice are defined as follows:

- If $Y\left(T_{i}\right)<Y_{k}$, do nothing and system is left as it is until next inspection time $T_{i+1}=T_{i}+\Delta T_{k}$.

- If $Y_{k} \leq Y\left(T_{i}\right)<Y_{f}$, system is serious deteriorated and needs to be preventively repaired.

- If $Y\left(T_{i}\right) \geq Y_{f}$, system is fault and needs to be correctively repaired.

As the degradation rate in the second stage $M_{2}$ is greater than the first stage $M_{1}$, the parameters of adaptive maintenance policy have the following relationship: $Y_{1}>Y_{2}, \Delta T_{1}>\Delta T_{2}$. The rule of adaptive maintenance policy is illustrated in Fig. 2.

\subsection{Time-dependent maintenance policy}

As the degradation rate is faster and faster in nonlinear degradation process, the interval of inspection should be shorter and shorter in terms of working time. The maintenance decision-making method that the interval of inspection changes over time is called time-dependent maintenance policy in this paper. In order to facilitate engineering ap-

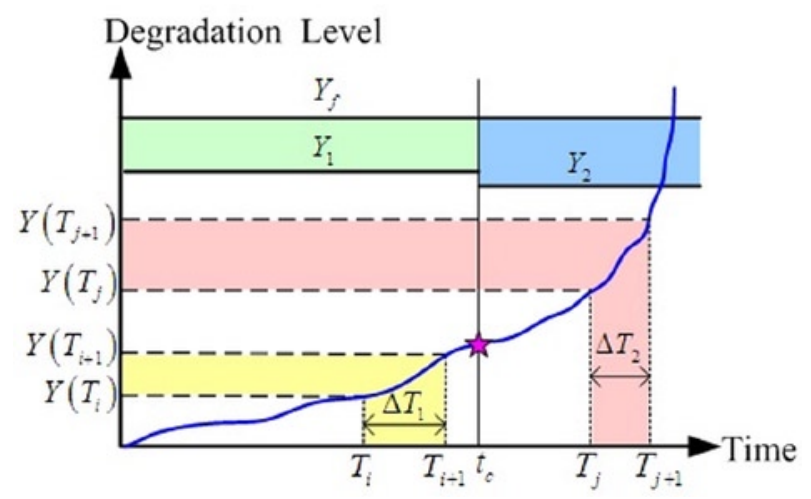

Fig. 2. Adaptive maintenance policy

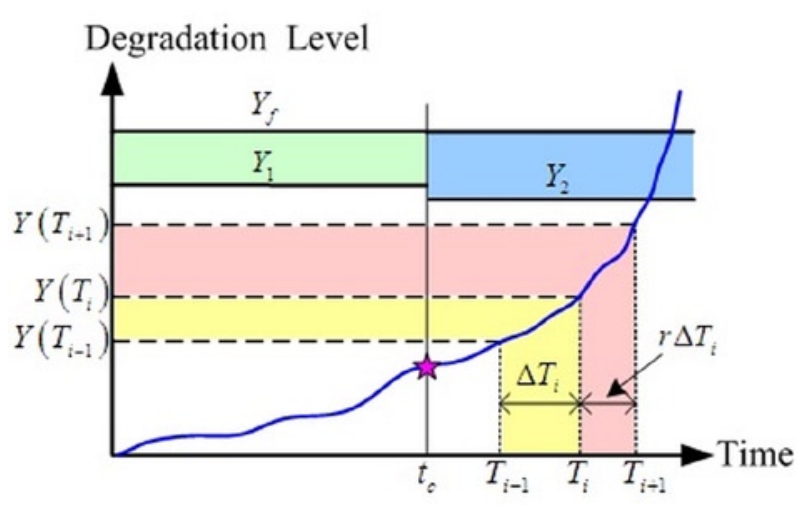

Fig. 3 Time-dependent maintenance policy plication, the $(i+1)$ th interval of inspection is $r$ times than $i$ th, namely $\Delta T^{i+1}=r \cdot \Delta T^{i}$ and $r<1$.

The rule of time-dependent maintenance policy (alarm threshold, possible maintenance action) is similar to adaptive maintenance policy, the only difference is that the interval of inspection $\Delta T^{i+1}=r \cdot \Delta T^{i}$. The rule of time-dependent maintenance policy is illustrated in Fig. 3.

\subsection{Maintenance policy evaluation}

\subsubsection{Evaluation method}

Maintenance cost occurs when a maintenance action is performed. The mean maintenance cost rate over an infinite time span is used to evaluate maintenance policy in this study. System is perfectly monitored through periodic monitor, and system state restores to be as good as new after a preventive/corrective maintenance action with negligible time. Mean maintenance cost rate can be obtained by renewal reward theory [20] as follows:

$$
E(C)=\lim _{t \rightarrow \infty} \frac{E[C(t)]}{t}=\frac{E[C(T)]}{E[T]}
$$

Where $C(t)$ is the total maintenance cost during time $[0, t], T$ is the mean time length of a renewal cycle.

The total maintenance cost in a renewal cycle $T$ can be written as:

$$
E[C(T)]=C_{I} E\left[N_{I}(T)\right]+C_{P} P_{P}+C_{C} P_{C}
$$

The mean time length of a renewal cycle $T$ can be expressed as

$$
E[T]=P_{P} T_{P}+P_{C} T_{f}
$$

\subsubsection{The probability of corrective maintenance}

According to the rule of maintenance policy, system is considered as failure if any one of the following events $\left(A_{C 1}, A_{C 2}, A_{C 3}\right)$ occurs. In other words, system needs to be correctively repaired and it will cause corrective maintenance $\operatorname{cost} C_{C}$. Take the event $A_{C 1}$ as a example, system degradation process is in stage $M_{1}\left(T_{z}<T_{z+1} \leq t_{c}\right)$, if the degradation level $Y\left(T_{z}\right)<Y_{1}$ for $z$ th inspection and $Y\left(T_{z+1}\right)>Y_{f}$ for $(z+1)$ th inspection, corrective maintenance action will be performed.

$$
\begin{aligned}
& A_{C 1}=\left\{Y\left(T_{z}\right)<Y_{1} \bigcap Y\left(T_{z+1}\right) \geq Y_{f} \bigcap T_{z}<T_{z+1} \leq t_{c}\right\} \\
& A_{C 2}=\left\{Y\left(T_{z}\right)<Y_{2} \bigcap Y\left(T_{z+1}\right) \geq Y_{f} \bigcap t_{c}<T_{z}<T_{z+1}\right\} \\
& A_{C 3}=\left\{Y\left(T_{z}\right)<Y_{1} \bigcap Y\left(T_{z+1}\right) \geq Y_{f} \bigcap T_{z}<t_{c} \leq T_{z+1}\right\}
\end{aligned}
$$

The probability for a corrective maintenance in a renewal cycle is the sums of probabilities for $A_{C 1}, A_{C 2}, A_{C 3}$. It is written as:

$$
P_{C}=P\left(A_{C 1}\right)+P\left(A_{C 2}\right)+P\left(A_{C 3}\right)
$$




\subsubsection{The probability of preventive maintenance}

It is considered that system needs to be preventively repaired if any one of the following events $\left(A_{P 1}, A_{P 2}, A_{P 3}\right)$ occurs, and it will cause preventive maintenance $\operatorname{cost} C_{P}$.

$$
\begin{aligned}
& A_{P 1}=\left\{Y\left(T_{z}\right)<Y_{1} \bigcap Y_{1} \leq Y\left(T_{z+1}\right)<Y_{f} \bigcap T_{z}<T_{z+1} \leq t_{c}\right\} \\
& A_{P 2}=\left\{Y\left(T_{z}\right)<Y_{2} \bigcap Y_{2} \leq Y\left(T_{z+1}\right)<Y_{f} \bigcap t_{c}<T_{z}<T_{z+1}\right\} \\
& A_{P 3}=\left\{Y\left(T_{z}\right)<Y_{1} \bigcap Y_{2} \leq Y\left(T_{z+1}\right)<Y_{f} \bigcap T_{z}<t_{c} \leq T_{z+1}\right\}
\end{aligned}
$$

The probability for a preventive maintenance in a renewal cycle is expressed as:

$$
P_{P}=P\left(A_{P 1}\right)+P\left(A_{P 2}\right)+P\left(A_{P 3}\right)
$$

\subsubsection{Continuous monitoring events}

The system is left until next inspection time if any one of the following events $\left(A_{I 1}, A_{I 2}\right)$ occurs, and it will cause monitoring $\operatorname{cost} C_{I}$.

$$
\begin{aligned}
& A_{I 1}=\left\{Y\left(T_{z}\right)<Y_{1} \bigcap T_{z} \leq t_{c}\right\} \\
& A_{I 2}=\left\{Y\left(T_{z}\right)<Y_{2} \bigcap T_{z}>t_{c}\right\}
\end{aligned}
$$

The probability for system left until next inspection in a renewal cycle can be written as:

$$
P_{I}=P\left(A_{I 1}\right)+P\left(A_{I 2}\right)
$$

The mean number of times of inspection actions in a renewal cycle $T$ is:

$$
E\left[N_{I}(T)\right]=\sum_{z=1}^{\infty} z P_{I}
$$

\subsubsection{Mean time length of a renewal cycle}

As formula (18) shown, the mean time length of a renewal cycle is determined by lifetime length $T_{f}$ when system ends with corrective maintenance and mean working time length $T_{P}$ when system ends with preventive maintenance. If the degradation level $Y(t)$ exceeds failure threshold $Y_{f}$, the system is considered as failed and will not work any time. That is to say, the lifetime length $T_{f}$ is the time interval for $Y(t)$ from initial value 0 to $Y_{f}$. However, the mean working time length $T_{P}$ does not mean that system cannot work. It is just shown that if a preventive maintenance action performed is better for system in inspection time $T_{z}$. Therefore, the system working time length when system ends with preventive maintenance is $T_{z}$.

\section{Numerical example}

This section aims to present some characteristics of two-stage degradation system: (a) In order to find the optimal maintenance policy for two-stage degradation system, mean cost rates of different main- tenance policy are compared. (b) For the purpose of improving the understanding in two-stage degradation system, the influences of different parameter in degradation modeling are analyzed. The following numerical evaluations of the maintenance cost rate for two-stage degradation system are obtained from Monte Carlo simulations.

\subsection{Choice of parameters values}

In this paper, the considered two-stage degradation system has the following features: The degradation process is linear and mean degradation rate is stationary in the first stage $M_{1}$, the model parameters are

$\alpha_{1}\left(t_{i+1}\right)=\alpha_{1}=1, \beta_{1}=1, \lambda_{1}=1, \eta_{1}=1, q_{1}=1$. The degradation process is nonlinear and mean degradation rate is change over time in the second stage $M_{2}$, the model parameters are $\alpha_{2}\left(t_{1}\right)=\alpha_{2}=1, \alpha_{2}\left(t_{i+1}\right)=q_{2} \cdot \alpha_{2}\left(t_{i}\right)=q_{2}{ }^{i} \cdot \alpha_{2}, \beta_{2}=1, \lambda_{2}=1$, and in order to present different nonlinear degradation process $\eta_{2}, q_{2}$ ( $\eta_{2}, q_{2}>1$ ) will been evaluated as the need of studying.

The failure threshold $Y_{f}$ is chosen in considering with the intrinsic properties of a two-stage degradation system. It is considered that $Y_{f}=200$ in this study. Meanwhile, in order to ensure the optimal result of mean cost rate $E(C)$ for maintenance policy is creditable, the unit costs are evaluated as other literatures $[5,7,17,19]$, so $C_{I}=5, C_{P}=50$, $C_{C}=100$.

Because the distribution of change-point $t_{c}$ is affected by many factors, it is difficult to determine the PDF of $t_{c}$. In this study, the $t_{c}$ PDF $g_{c}(t)$ is assumed to follow uniform distribution for the convenience of calculation. In order to analyze the influence of $t_{c}$, different uniform distribution of $t_{c}$ are considered:

- Whole change-point distribution: $t_{c} \sim U(1,120)$.

- Early change-point distribution: $t_{c} \sim U(1,60)$.

- Middle change-point distribution: $t_{c} \sim U(30,90)$.

- Late change-point distribution: $t_{c} \sim U(60,120)$.

The upper bound value of the uniform distribution is evaluated as 120 , it is considered that system fault occurs mostly in the second degradation stage $M_{2}$ on this occasion. Early and late change-point distributions present the first and second half of whole change-point distribution, respectively.

\subsection{Influence of maintenance policy}

The degradation level monitoring method for different maintenance policy is different, which includes alarm threshold and interval of inspection. Meanwhile, the mean maintenance cost rate is impacted by monitoring method. The method for obtaining optimal parameters and minimum mean cost rate of maintenance policy has been mentioned in some literatures $[10,17]$. The optimal parameters of main-

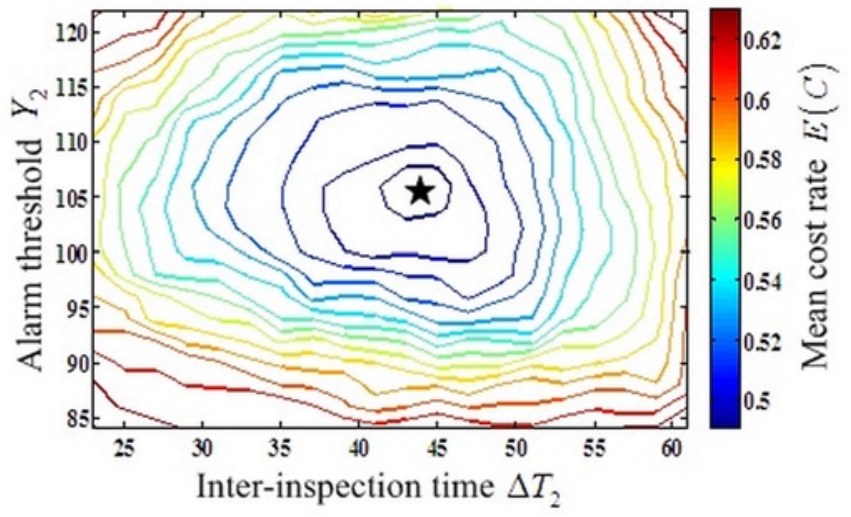

Fig. 4. Mean cost rate $E(C)$ when $Y_{1}=126, \Delta T_{1}=71, t_{c} \sim U(30,90)$ 
Table 1. Influence of maintenance policy and tc when shock damage change $\left(\eta_{2}=1, q_{2}=1.01\right)$

\begin{tabular}{|c|c|c|c|c|}
\hline Change-point & Maintenance policy & Optimal parameters & Mean cost rate & Impact \\
\hline \multirow{2}{*}{$t_{c} \sim U(1,120)$} & Adaptive & $\begin{array}{l}Y_{1}=126, \Delta T_{1}=76 \\
Y_{2}=109, \Delta T_{2}=38\end{array}$ & $E_{1}(C)=0.4827$ & \\
\hline & Time-dependent & $\begin{array}{l}Y_{1}=122, \Delta T_{1}=74 \\
Y_{2}=102, r=0.66\end{array}$ & $E_{2}(C)=0.4608$ & $\begin{array}{l}0.0219 \\
(4.54 \%)\end{array}$ \\
\hline \multirow{2}{*}{$t_{c} \sim U(1,60)$} & Adaptive & $\begin{array}{l}Y_{1}=128, \Delta T_{1}=73 \\
Y_{2}=104, \Delta T_{2}=34\end{array}$ & $E_{1}(C)=0.5478$ & \\
\hline & Time-dependent & $\begin{array}{l}Y_{1}=122, \Delta T_{1}=71 \\
Y_{2}=102, r=0.60\end{array}$ & $E_{2}(C)=0.5341$ & $\begin{array}{c}0.0137 \\
(2.50 \%)\end{array}$ \\
\hline \multirow{2}{*}{$t_{c} \sim U(30,90)$} & Adaptive & $\begin{array}{l}Y_{1}=126, \Delta T_{1}=71 \\
Y_{2}=103, \Delta T_{2}=44\end{array}$ & $E_{1}(C)=0.4803$ & \\
\hline & Time-dependent & $\begin{array}{l}Y_{1}=125, \Delta T_{1}=72 \\
Y_{2}=105, r=0.69\end{array}$ & $E_{2}(C)=0.4622$ & $\begin{array}{c}0.0181 \\
(3.77 \%)\end{array}$ \\
\hline \multirow{2}{*}{$t_{c} \sim U(60,120)$} & Adaptive & $\begin{array}{l}Y_{1}=126, \Delta T_{1}=74 \\
Y_{2}=107, \Delta T_{2}=51\end{array}$ & $E_{1}(C)=0.4421$ & \\
\hline & Time-dependent & $\begin{array}{l}Y_{1}=128, \Delta T_{1}=74 \\
Y_{2}=108, r=0.78\end{array}$ & $E_{2}(C)=0.4204$ & $\begin{array}{c}0.0217 \\
(4.91 \%)\end{array}$ \\
\hline
\end{tabular}

Table 2. Influence of maintenance policy and tc when shock counting change $\left(q_{2}=1, \eta_{2}=1.1\right)$

\begin{tabular}{|c|c|c|c|c|}
\hline Change-point & Maintenance policy & Optimal parameters & Mean cost rate & Impact \\
\hline \multirow{2}{*}{$t_{c} \sim U(1,120)$} & Adaptive & $\begin{array}{l}Y_{1}=128, \Delta T_{1}=73 \\
Y_{2}=114, \Delta T_{2}=53\end{array}$ & $E_{1}(C)=0.4763$ & \\
\hline & Time-dependent & $\begin{array}{l}Y_{1}=131, \Delta T_{1}=73 \\
Y_{2}=111, r=0.69\end{array}$ & $E_{2}(C)=0.4522$ & $\begin{array}{c}0.0241 \\
(5.06 \%)\end{array}$ \\
\hline \multirow{2}{*}{$t_{c} \sim U(1,60)$} & Adaptive & $\begin{array}{l}Y_{1}=131, \Delta T_{1}=75 \\
Y_{2}=113, \Delta T_{2}=45\end{array}$ & $E_{1}(C)=0.5182$ & \\
\hline & Time-dependent & $\begin{array}{l}Y_{1}=134, \Delta T_{1}=72 \\
Y_{2}=110, r=0.63\end{array}$ & $E_{2}(C)=0.5047$ & $\begin{array}{l}0.0135 \\
(2.61 \%)\end{array}$ \\
\hline \multirow{2}{*}{$t_{c} \sim U(30,90)$} & Adaptive & $\begin{array}{l}Y_{1}=126, \Delta T_{1}=72 \\
Y_{2}=116, \Delta T_{2}=55\end{array}$ & $E_{1}(C)=0.4751$ & \\
\hline & Time-dependent & $\begin{array}{l}Y_{1}=130, \Delta T_{1}=69 \\
Y_{2}=111, r=0.81\end{array}$ & $E_{2}(C)=0.4544$ & $\begin{array}{c}0.0207 \\
(4.36 \%)\end{array}$ \\
\hline \multirow{2}{*}{$t_{c} \sim U(60,120)$} & Adaptive & $\begin{array}{l}Y_{1}=129, \Delta T_{1}=75 \\
Y_{2}=114, \Delta T_{2}=60\end{array}$ & $E_{1}(C)=0.4269$ & \\
\hline & Time-dependent & $\begin{array}{l}Y_{1}=129, \Delta T_{1}=75 \\
Y_{2}=108, r=0.84\end{array}$ & $E_{2}(C)=0.4024$ & $\begin{array}{c}0.0245 \\
(5.74 \%)\end{array}$ \\
\hline
\end{tabular}

tenance policy can be achieved after simulations. That is to say, the mean maintenance cost rate $E(C)$ can be found under simulations with different alarm threshold and interval of inspection. Take adaptive maintenance policy as an example, as maintenance policy evaluation method studies in section 3.3, the minimum mean cost rate is $E(C)=0.4803$ when $Y_{1}=126, Y_{2}=103, \Delta T_{1}=71$, $\Delta T_{2}=44$ and $t_{c} \sim U(30,90)$, as shown in contour map Fig. $4(E(C)$ are equal in the same contour). All the optimal parameters of maintenance policy under different cases can be achieved by a similar way.

As adaptive maintenance policy has been proved to be effective by Ponchet [19], taking the mean cost rate of adaptive maintenance policy as a basis of comparison. For instance (as Tab. 1 shown), when $t_{c} \sim U(30,90)$, $\eta_{2}=1, q_{2}=1.01$, the minimum mean cost rate of adaptive maintenance policy is $E_{1}(C)=0.4803$, and the minimum mean cost rate of time-dependent maintenance policy is $E_{2}(C)=0.4622 . E_{2}(C)$ have a decrease of 0.0181 compares to $E_{1}(C)$, so that the optimal rate is $0.0181 / 0.4803=3.77 \%$.

Nonlinear degradation process can be expressed by shock damage change and shock counting change. As shown in Tab. $1\left(\eta_{2}=1, q_{2}=1.01\right)$ and Tab. 2 ( $\left.t_{c} \sim U(1,120)\right)$, it is obvious that the mean cost rate of time-dependent maintenance policy is smaller than adaptive maintenance policy. In other words, time-dependent maintenance policy is better than adaptive maintenance policy for given system. Because degradation rate in stage $M_{2}$ for given system is nonlinear and becomes faster and faster over working time, and the interval of inspection in stage $M_{2}$ for time-dependent maintenance policy $\Delta T_{2}$ is shorter and shorter as inspection time goes on. But the interval of inspection for adaptive maintenance policy $\Delta T_{2}$ is fixed and never changed in stage $M_{2}$.

\subsection{Influence of change-point distribution}

The time distribution of change-point $t_{c}$ can influence the choice of system maintenance policy. Hence, the influence of change-point distribution is studied under both maintenance policies. The optimal results under different $t_{c}$ distribution for shock damage change and shock counting change are shown in Tab. 1 and Tab. 2, respectively. Taking Tab. 1 as an example, the analyzed results can be achieved as follows:

(a) Although the $t_{c}$ distribution and maintenance policy are different, the variety of alarm thresholds $\left(Y_{1}\right)$ and intervals of inspection $\left(\Delta T_{1}\right)$ for the first degradation stage $M_{1}$ is very small. The change of alarm thresholds $\left(Y_{2}\right)$ for the second degradation stage $M_{2}$ is also very small, but the variety of intervals of inspection $\left(\Delta T_{2}\right)$ is great. It is because that mean system lifetime is change corresponding to different $t_{c}$ distribution, the earlier change-point $t_{c}$ occurs, the shorter mean system lifetime.

(b) When $t_{c}$ fall in time interval $(1,60),(30,90)$ and $(60,120)$, the mean cost rates for adaptive maintenance policy are $0.5478,0.4803$ and 0.4421 , respectively. It means that the mean maintenance cost rate is drop off with the increase of average time of $t_{c}$ distribution. This feature also conforms to time-dependent maintenance policy. 
Table 3. Influence of shock damage change $\left(\eta_{2}=1, t_{c} \sim U(30,90)\right)$

\begin{tabular}{|c|c|c|c|c|}
\hline Model parameter & Maintenance policy & Optimal parameters & Mean cost rate & Impact \\
\hline \multirow{2}{*}{$q_{2}=1.000$} & Adaptive & $\begin{array}{l}Y_{1}=124, \Delta T_{1}=75 \\
Y_{2}=124, \Delta T_{2}=75\end{array}$ & $E_{1}(C)=0.3750$ & \\
\hline & Time-dependent & $\begin{array}{l}Y_{1}=126, \Delta T_{1}=85 \\
Y_{2}=126, r=0.80\end{array}$ & $E_{2}(C)=0.3711$ & $\begin{array}{c}0.0039 \\
(1.04 \%)\end{array}$ \\
\hline \multirow{2}{*}{$q_{2}=1.005$} & Adaptive & $\begin{array}{l}Y_{1}=126, \Delta T_{1}=74 \\
Y_{2}=115, \Delta T_{2}=62\end{array}$ & $E_{1}(C)=0.4270$ & \\
\hline & Time-dependent & $\begin{array}{l}Y_{1}=122, \Delta T_{1}=74 \\
Y_{2}=110, r=0.84\end{array}$ & $E_{2}(C)=0.4141$ & $\begin{array}{r}0.0129 \\
(3.02 \%)\end{array}$ \\
\hline \multirow{2}{*}{$q_{2}=1.010$} & Adaptive & $\begin{array}{l}Y_{1}=126, \Delta T_{1}=71 \\
Y_{2}=103, \Delta T_{2}=44\end{array}$ & $E_{1}(C)=0.4803$ & \\
\hline & Time-dependent & $\begin{array}{l}Y_{1}=125, \Delta T_{1}=72 \\
Y_{2}=105, r=0.69\end{array}$ & $E_{2}(C)=0.4622$ & $\begin{array}{c}0.0181 \\
(3.77 \%)\end{array}$ \\
\hline \multirow{2}{*}{$q_{2}=1.015$} & Adaptive & $\begin{array}{l}Y_{1}=124, \Delta T_{1}=68 \\
Y_{2}=104, \Delta T_{2}=39\end{array}$ & $E_{1}(C)=0.5207$ & \\
\hline & Time-dependent & $\begin{array}{l}Y_{1}=122, \Delta T_{1}=71 \\
Y_{2}=103, r=0.63\end{array}$ & $E_{2}(C)=0.4970$ & $\begin{array}{l}0.0237 \\
(4.55 \%)\end{array}$ \\
\hline \multirow{2}{*}{$q_{2}=1.020$} & Adaptive & $\begin{array}{l}Y_{1}=123, \Delta T_{1}=68 \\
Y_{2}=106, \Delta T_{2}=35\end{array}$ & $E_{1}(C)=0.5569$ & \\
\hline & Time-dependent & $\begin{array}{l}Y_{1}=128, \Delta T_{1}=68 \\
Y_{2}=99, r=0.60\end{array}$ & $E_{2}(C)=0.5257$ & $\begin{array}{c}0.0312 \\
(5.60 \%)\end{array}$ \\
\hline
\end{tabular}

(c) As shown in section 4.2, time-dependent maintenance policy is better than adaptive maintenance policy for given system. The optimal rates are $2.50 \%, 3.77 \%$ and $4.91 \%$ when $t_{c}$ fall in time interval $(1,60),(30,90)$ and $(60,120)$, respectively. It is obvious that there is more interest in using a time-dependent maintenance policy instead of an adaptive maintenance policy when the changepoint $t_{c}$ occurs more later.

(d) When $t_{c}$ fall in time interval $(1,120)$ and $(30,90)$, the optimal rates are $4.54 \%$ and $3.77 \%$, respectively. The average time of both $(1,120)$ and $(30,90)$ equal to 60 . It can be known that when the change-point $t_{c}$ is defined on a larger time interval the more interest can be achieved in using a time-dependent maintenance policy instead of an adaptive maintenance policy.

\subsection{Influence of nonlinear degradation process}

As shown in Tab. 3 and Tab. 4, different model parameters $\eta_{2}$ and $q_{2}$ present different nonlinear degradation process. The larger of $\eta_{2}$ and $q_{2}$, the faster of degradation rate increase in the second stage $M_{2}$. When $\eta_{1}=\eta_{2}=1$ and $q_{1}=q_{2}=1$, the system mean degradation rate is stationary and never change, the degradation process is linear and single-stage.
The optimal results under different model parameters $q_{2}$ for shock damage change are shown in Tab. 3, and the optimal results under different model parameters $\eta_{2}$ for shock counting change are shown in Tab. 4. The optimal results are similar between Tab. 3 and Tab. 4. Taking Tab. 3 as an example, the analyzed results can be achieved as follows:

(a) Because degradation process is linear and degradation rate is stationary in the first stage $M_{1}$ for considered system, the variety of alarm thresholds $\left(Y_{1}\right)$ and intervals of inspection $\left(\Delta T_{1}\right)$ for stage $M_{1}$ is very small although $q_{2}$ are different, especially for adaptive maintenance policy.

(b) As the growth of model parameter $q_{2}$, the alarm thresholds $\left(Y_{2}\right)$ and intervals of inspection $\left(\Delta T_{2}\right)$ for stage $M_{2}$ become smaller and smaller. For example, $q_{2}$ equal to $1.000,1.005,1.010,1.015$ and 1.020 , the intervals of inspection of adaptive maintenance policy are $75,62,44,39$ and 35 , respectively.

(c) When $q_{2}$ equal to $1.000,1.005,1.010,1.015$ and 1.020 , the mean cost rates for adaptive maintenance policy are $0.3750,0.4270$, $0.4803,0.5207$ and 0.5569 , respectively. It means that the mean maintenance cost rate is going up with the increase of model parameter $q_{2}$. This feature also conforms to time-dependent maintenance policy.

(d) As seen previously, the optimal rates are $1.04 \%, 3.02 \%, 3.77 \%$, $4.55 \%$ and $5.60 \%$ when $q_{2}$ equal to $1.000,1.005,1.010,1.015$ and 1.020 , respectively. It is obviously that there is more interest in using a time-dependent maintenance policy instead of an 
Table 4. Influence of shock counting change $\left(q_{2}=1, t_{c} \sim U(30,90)\right.$ )

\begin{tabular}{|c|c|c|c|c|}
\hline Model parameter & Maintenance policy & Optimal parameters & Mean cost rate & Impact \\
\hline \multirow{2}{*}{$\eta_{2}=1$} & Adaptive & $\begin{array}{l}Y_{1}=126, \Delta T_{1}=76 \\
Y_{2}=126, \Delta T_{2}=76\end{array}$ & $E_{1}(C)=0.3776$ & \\
\hline & Time-dependent & $\begin{array}{l}Y_{1}=124, \Delta T_{1}=76 \\
Y_{2}=118, r=0.87\end{array}$ & $E_{2}(C)=0.3745$ & $\begin{array}{c}0.0031 \\
(0.82 \%)\end{array}$ \\
\hline \multirow{2}{*}{$\eta_{2}=1.05$} & Adaptive & $\begin{array}{l}Y_{1}=126, \Delta T_{1}=77 \\
Y_{2}=118, \Delta T_{2}=65\end{array}$ & $E_{1}(C)=0.4118$ & \\
\hline & Time-dependent & $\begin{array}{l}Y_{1}=126, \Delta T_{1}=78 \\
Y_{2}=116, r=0.73\end{array}$ & $E_{2}(C)=0.4017$ & $\begin{array}{c}0.0101 \\
(2.45 \%)\end{array}$ \\
\hline \multirow{2}{*}{$\eta_{2}=1.1$} & Adaptive & $\begin{array}{l}Y_{1}=126, \Delta T_{1}=72 \\
Y_{2}=116, \Delta T_{2}=55\end{array}$ & $E_{1}(C)=0.4751$ & \\
\hline & Time-dependent & $\begin{array}{l}Y_{1}=130, \Delta T_{1}=69 \\
Y_{2}=111, r=0.81\end{array}$ & $E_{2}(C)=0.4544$ & $\begin{array}{c}0.0207 \\
(4.36 \%)\end{array}$ \\
\hline \multirow{2}{*}{$\eta_{2}=1.15$} & Adaptive & $\begin{array}{l}Y_{1}=126, \Delta T_{1}=71 \\
Y_{2}=118, \Delta T_{2}=47\end{array}$ & $E_{1}(C)=0.5241$ & \\
\hline & Time-dependent & $\begin{array}{l}Y_{1}=126, \Delta T_{1}=66 \\
Y_{2}=116, r=0.71\end{array}$ & $E_{2}(C)=0.4926$ & $\begin{array}{l}0.0315 \\
(6.01 \%)\end{array}$ \\
\hline \multirow{2}{*}{$\eta_{2}=1.2$} & Adaptive & $\begin{array}{l}Y_{1}=124, \Delta T_{1}=75 \\
Y_{2}=111, \Delta T_{2}=39\end{array}$ & $E_{1}(C)=0.5615$ & \\
\hline & Time-dependent & $\begin{array}{l}Y_{1}=128, \Delta T_{1}=63 \\
Y_{2}=112, r=0.59\end{array}$ & $E_{2}(C)=0.5191$ & $\begin{array}{c}0.0424 \\
(7.55 \%)\end{array}$ \\
\hline
\end{tabular}

adaptive maintenance policy when model parameter $q_{2}$ greater. Meanwhile, when $q_{2}=1$ the system mean degradation rate is fixed in whole degradation process, the alarm thresholds and inter-inspection times for both stage $M_{1}$ and $M_{2}$ are equal. In this case, the adaptive maintenance policy is the same to traditional conditionbased maintenance policy (namely global maintenance policy [17]), and it is no necessary to use a time-dependent maintenance policy instead of an adaptive maintenance policy.

\section{Conclusions}

This paper takes into account degradation modeling and maintenance policy for a two-stage degradation system, which degradation process is nonlinear and degradation rate is change over time in both stages. The system degradation process is considered as step, and it is modeled based on cumulative damage model. The nonlinear degrada- tion process is modeled by shock damage change and shock counting change. In order to explore optimal maintenance policy for considered system, two maintenance policies have been investigated and assessed through their mean maintenance cost rates.

Moreover, influence analysis of different model parameter and maintenance policy is studied in numerical examples, and results prove that: (a) It is necessary to consider monitoring method for considered system, optimal maintenance policy can help to reduce mean cost rate. (b) It is obvious that the mean maintenance cost rate and maintenance policy are impacted by change-point distribution, shock damage and shock counting.

\section{Acknowledgements}

This research report was partially supported by science fund for youths under grant number 71401173 .

\section{References}

1. Bae SJ, Kuo W, Kvam PH. Degradation models and implied lifetime distributions. Reliability Engineering and System Safety 2007; 92:601608, http://dx.doi.org/10.1016/j.ress.2006.02.002.

2. Bae SJ, Yuan T, Ning S, Kuo W. A Bayesian approach to modeling two-phase degradation using change-point regression. Reliability Engineering and System Safety 2015; 134:66-74, http://dx.doi.org/10.1016/j.ress.2014.10.009.

3. Chen N, Tsui KL. Condition monitoring and remaining useful life prediction using degradation signals: revisited. IIE Transactions 2013; 45(9):939-952, http://dx.doi.org/10.1080/0740817X.2012.706376.

4. Farid A, David P. Estimating arrival rate of nonhomogeneous Poisson processes with semidefinite programming. Ann Oper Res 2013; 208:291-308, http://dx.doi.org/10.1007/s10479-011-1020-2. 
5. Fouladirad M, Grall A. A maintenance decision rule with embedded Bayesian online change detection for gradually deteriorating systems. Journal of Risk and Reliability 2008; 22(3):359-369.

6. Fouladirad M, Grall A. Condition-based maintenance for a system subject to a non-homogeneous wear process with a wear rate transition. Reliability Engineering and System Safety 2011; 96:611-618, http://dx.doi.org/10.1016/j.ress.2010.12.008.

7. Fouladirad M, Grall A, Dieulle L. On the use of on-line detection for maintenance of gradually deteriorating systems. Reliability Engineering and System Safety 2008; 93(12):1814-1820, http://dx.doi.org/10.1016/j.ress.2008.03.020.

8. Gebraeel NZ, Lawley MA, Li R, Ryan JK. Residual-life distributions from component degradation signals: a Bayesian approach. IIE Transactions 2005; 37(6):543-557, http://dx.doi.org/10.1080/07408170590929018.

9. Guo CM. Condition-based Maintenance Optimization with independent increments processes. National University of Defense Technology, Changsha, China, 2013,07.

10. Huynh KT, Barros A, Be'renguer C, Castro IT. A periodic inspection and replacement policy for systems subject to competing failure modes due to degradation and traumatic events. Reliability Engineering and System Safety 2011; 96:497-508, http://dx.doi.org/10.1016/j. ress.2010.12.018.

11. Jiang RY, Prabhakar Murthy DN. Maintenance decision models for management. Science Press, 2008,06.

12. Keedy E, Feng Q. A physics-of-failure based reliability and maintenance modeling framework for stent deployment and operation. Reliability Engineering and System Safety 2012; 103:94-101, http://dx.doi.org/10.1016/j.ress.2012.03.005.

13. Meier-Hirmer C, Sourget F, Roussignol M. Maintenance optimization for a system with a gamma deterioration process and intervention delay: application to track maintenance. Journal of Risk and Reliability 2009; 223(3):189-198, http://dx.doi.org/10.1243/1748006XJRR234.

14. Ni XL, Zhao JM, Wang GY, Teng HZ. Maintenance policy for two-stage deteriorating mode system based on cumulative damage model. Journal of Vibroengineering 2015; 17(3):1266-1285.

15. Noortwijk van JM. A survey of the application of gamma processes in maintenance. Reliability Engineering and System Safety 2009; 94:221, http://dx.doi.org/10.1016/j.ress.2007.03.019.

16. Peng W, Li YF, Yang YJ, Huang HZ, Zuo MJ. Inverse Gaussian process models for degradation analysis: a Bayesian perspective. Reliability Engineering and System Safety 2014; 130:175-189, http://dx.doi.org/10.1016/j.ress.2014.06.005.

17. Ponchet A, Fouladirad M, Grall A. Assessment of a maintenance model of a multi-deteriorating mode system. Reliability Engineering and System Safety 2010; 95(11):1244-1254, http://dx.doi.org/10.1016/j.ress.2010.06.021.

18. Qian CH, Nakamura S, Nakagawa T. Cumulative damage model with two kinds of shocks and its application to the backup policy. Journal of the Operations Research 1999; 42(4):501-511.

19. Saassouh B, Dieulle L, Grall A. Online maintenance policy for a deterioration system with random change of mode. Reliability Engineering and System Safety 2007; 92(12):1677-1685, http://dx.doi.org/10.1016/j.ress.2006.10.017.

20. Sheldon MR. Stochastic processes for insurance and finance, wiley series in probability and statistics. Johon Wiley \& Sons, New York, 1996:1-639.

21. Song SL, Coit DW, Feng QM, Peng H. Reliability analysis for multi-component systems subject to multiple dependent competing failure process. IEEE Transactions on Reliability 2014; 63:331-345, http://dx.doi.org/ 10.1109/TR.2014.2299693.

22. Toshio N. Shock and damage models in reliability theory. Springer, 2006,06.

23. Wang X, Balakrishnan N, Guo B. Residual life estimation based on a generalized Wiener degradation process. Reliability Engineering and System Safety 2014; 124:13-23, http://dx.doi.org/10.1016/j.ress.2013.11.011.

24. Ye ZS, Tang LC, Xu HY. A distribution-based systems reliability model under extreme shocks and natural degradation. IEEE Transactions on Reliability 2011; 60(1):246-256, http://dx.doi.org/10.1109/TR.2010.2103710.

25. Zhao Z, Wang FL, Jia MX, Wang S. Predictive maintenance policy based on process data. Chemometrics and Intelligent Laboratory Systems 2010; 103:137-143, http://dx.doi.org/10.1016/j.chemolab.2010.06.009.

\section{Xianglong NI \\ Jianmin ZHAO \\ Wenyuan SONG \\ Chiming GUO \\ Haiping LI}

Mechanical Engineering College

Shijiazhuang, 050003, Hebei province, China

E-mails: ni_phm@163.com,jm_zhao@hotmail.com, phm_cbm@163.com,guochiming@nudt.edu.cn, hp_li@hotmail.com 